\title{
Qualidade de produtos a base de plantas medicinais comercializados no Brasil: castanha-da-índia (Aesculus hippocastanum L.), capim-limão (Cymbopogon citratus (DC.) Stapf) e centela (Centella asiatica (L.) Urban) ${ }^{1}$
}

\author{
Joabe Gomes de $\mathrm{Melo}^{2}$, Járisson Diógenes Guilherme da Rocha Martins ${ }^{3}$, Elba Lúcia Cavalcanti de Amorim³ e \\ Ulysses Paulino de Albuquerque ${ }^{2,4}$
}

Recebido em 6/03/2006. Aceito em 1/08/2006

\begin{abstract}
RESUMO - (Qualidade de produtos a base de plantas medicinais comercializados no Brasil: castanha-da-índia (Aesculus hippocastanum L.) capim-limão (Cymbopogon citratus (DC.) Stapf) e centela (Centella asiatica (L.) Urban). Com o objetivo de avaliar a qualidade de produtos a base de plantas medicinais, analisou-se dez amostras de castanha-da-índia, onze de capim-limão e seis de centela, comercializadas em farmácias da cidade do Recife, provenientes de indústrias de várias partes do país. Analisamos as informações técnico-científicas nos rótulos e/ou bulas de acordo com as exigências e obrigatoriedades da legislação brasileira (RDC n. 140 de 29/05/2003 e na RDC n. 102 de 30/11/2000), e embasamento da literatura científica. Também avaliou-se as características organolépticas, a autenticidade e a pureza dos produtos. Constatou-se ausência das informações obrigatórias em 92,59\% das amostras. Dentre os termos vedados, foi comum a sugestão da inexistência de efeitos colaterais ou adversos. Quanto as indicações terapêuticas não se observou padronização técnica dos termos nem comprovação científica para algumas das atividades atribuídas pelos fabricantes. Todas as amostras foram consideradas autênticas com base nos testes fitoquímicos e farmacobotânicos. Na análise da pureza 59,26\% das amostras foram reprovadas, devido principalmente ao elevado teor de umidade e cinzas totais. Constata-se que além dos produtos comercializados carecerem de informações e qualidade adequadas, há necessidade urgente de uma fiscalização efetiva por parte dos órgãos competentes.
\end{abstract}

Palavras-chave: plantas medicinais, fitoterápicos, controle de qualidade, produtos naturais, botânica aplicada

\begin{abstract}
Quality of products made from medicinal plants commercialized in Brazil: horsechestnut (Aesculus hippocastanum L.), lemongrass (Cymbopogon citratus (DC.) Stapf), and gotu kola (Centella asiatica (L.) Urban). Aiming to evaluate the quality of products made from medicinal plants, there were analyzed ten samples of horsechestnut, eleven samples of lemongrass, and six samples of gotu kola commercialized in pharmacies from the city of Recife (Pernambuco, Brazil), coming from industries of several parts of the country. We analyzed the technical-scientific information on the labels and/or directions according to the requirements and obligations of Brazilian law (laws "RDC 140 of 29/05/2003" and "RDC 102 of 30/11/2000") and to scientific literature embasement. The products' organoleptic characteristics, authenticity, and purity were also evaluated. The absence of obligatory information was verified in $92.59 \%$ of the samples. Among the blacked terms, it was common to find products that suggested inexistent collateral or adverse effects. Technical terms were not standardized and the manufacturers did not provide scientific proof for some of the activities credited to the products. All samples were considered authentic based on the phytochemical and pharmacobotanical tests. The purity analysis considered $59.26 \%$ of the samples inappropriate, mainly due to the high total levels of humidity and ashes. It was verified that besides the lack of adequate information and quality of the commercialized products, there is an urgent need for an effective inspection by the suitable agencies.
\end{abstract}

Key words: medicinal plants, phytotherapy, quality control, natural products, applied botany

\section{Introdução}

O tratamento das enfermidades humanas a partir de plantas medicinais, ou seus derivados, é uma prática antiga e que atualmente encontra-se em expansão por todo o mundo. Calcula-se que no ano de 2000 os produtos a base de plantas medicinais movimentaram cerca de 30 bilhões de dólares (Engelke 2003). Aliado a isso, a Organização Mundial da Saúde estima que $80 \%$ das pessoas dependam da medicina tradicional,

\footnotetext{
1 Parte da dissertação de Mestrado do primeiro Autor, Programa de Pós-Graduação em Botânica da UFRPE

2 Universidade Federal Rural de Pernambuco, Departamento de Biologia, Laboratório de Etnobotânica Aplicada, Área de Botânica, Rua Dom Manoel de Medeiros s/n, Dois Irmãos, 52171-900 Recife, PE, Brasil

3 Universidade Federal de Pernambuco, Departamento de Ciências Farmacêuticas, Laboratório de Química Farmacêutica, Avenida Professor Moraes Rego 1235, Cidade Universitária, 50670-901 Recife, PE, Brasil

4 Autor para correspondência: upa@db.ufrpe.br
} 
em especial nas nações em desenvolvimento (Farnsworth 1997). A fitoterapia tem ressurgido como uma opção medicamentosa bem aceita e acessível aos povos do Mundo, e no caso do Brasil é adequada para as necessidades locais de centenas de municípios brasileiros no atendimento primário à saúde (Eldin \& Dunford 2001).

A expansão da fitoterapia pode ser atribuída a diversos fatores tais como: aos efeitos adversos de fármacos sintéticos, a preferência dos consumidores por tratamentos "naturais", a validação científica das propriedades farmacológicas de espécies vegetais, o desenvolvimento de novos métodos analíticos colocados à disposição do controle de qualidade, o desenvolvimento de novas formas de preparações e administrações de produtos fitoterápicos, um melhor conhecimento químico, farmacológico e clínico das drogas vegetais e seus derivados, além também do menor custo se comparado com os fármacos sintéticos (Cañigueral et al. 2003; Vieira 2001).

O Brasil possui uma farmacopéia popular muito diversa baseada em plantas medicinais, resultado de uma miscigenação cultural envolvendo africanos, europeus e indígenas, com introdução de espécies exóticas pelos colonizadores e escravos. Além disso, o país possui a maior diversidade vegetal do planeta, aproximadamente 55 mil espécies de plantas superiores (Engelke 2003). Como conseqüência da grande difusão e utilização das plantas medicinais, as indústrias vêm produzindo produtos à base de espécies vegetais, de diversas formas farmacêuticas, que têm sido comercializados em farmácias, supermercados e casas de produtos naturais. Contudo, não há garantia para a grande maioria desses produtos, quanto a sua eficácia, segurança e qualidade.

A segurança e a eficácia dos produtos dependem de diversos fatores, dentre estes se pode destacar a qualidade do produto comercializado. Segundo Farias (2001) a eficácia é dada pela comprovação, por meio de ensaios farmacológicos pré-clínicos e clínicos, dos efeitos biológicos preconizados para esses recursos terapêuticos, e a segurança é determinada pelos ensaios que comprovam a ausência de efeitos tóxicos. No entanto, a má qualidade de um produto fitoterápico ou droga vegetal pode vir a anular a sua eficácia e trazer riscos à saúde do consumidor. Melo et al. (2004) enfatizam que a fraude e a má qualidade em fitoterápicos são motivos de preocupação por parte dos profissionais da área de saúde e da comunidade científica, pois interferem na eficácia e segurança do produto.
Devido a grande demanda por produtos a base de plantas medicinais, conseqüência do significativo aumento do interesse do público brasileiro por "terapias naturais", se faz necessário investigar como esses produtos estão sendo oferecidos ao consumidor, de acordo com a legislação específica e critérios estabelecidos cientificamente. As pesquisas com esta orientação são escassas na região Nordeste (Nascimento et al. 2005a; Nascimento et al. 2005b; Carvalho et al. 2004; Amaral et al. 2003), particularmente nos grandes centros urbanos, como Recife, onde se observa um elevado comércio de produtos medicinais de diversas formas (cf. Ramos et al. 2005; Albuquerque et al. 2007) sem uma fiscalização efetiva da qualidade e garantias de eficácia e segurança.

Três espécies são amplamente utilizadas como recurso terapêutico por grande parte da população brasileira, inclusive sendo empregadas em produtos industrializados com indicações terapêuticas, e comercializados nas mais diversas formas farmacêuticas, e que são alvo deste trabalho, são elas: Aesculus hippocastanum L., Centella asiatica (L.) Urban e Cymbopogon citratus (D.C.) Stapf.

Aesculus hippocastanum L., conhecida popularmente como castanha-da-índia, pertence à família Hippocastanaceae. É uma árvore nativa do Oeste da Ásia, sendo grandemente cultivada em parques, jardins e ao longo de avenidas metropolitanas de vários países de todo o mundo (WHO 1999). As partes usadas para fins medicinais são as sementes que devem estar secas e maduras, as quais contêm escina (mistura natural de saponinas triterpênicas) que é o princípio ativo da espécie. A este componente químico são atribuídas propriedades anti-edema, antiinflamatórias e venotônicas, sendo a sua maior indicação clínica para o tratamento da insuficiência venosa crônica, todas suportadas por investigações experimentais (Sirtori 2001).

Centella asiatica (L.) Urban, conhecida vulgarmente no Brasil por centela, é uma erva da família Apiaceae. É oriunda de regiões quentes de ambos os hemisférios (incluindo África, Austrália, Camboja, América Central, China, Indonésia, América do Sul, Tailândia e Sul dos Estados Unidos), sendo abundante em áreas pantanosas da Índia, Iran e Paquistão (WHO 1999). As partes aéreas da planta contêm triterpenos, ácido asiático e ácido madecássico e seus derivados triterpenos éster glicosilados asiaticosídeo e madecassosídeo (Inamdar et al. 1996). Pesquisas atestaram suas propriedades antioxidantes (Jayashree et al. 2003), e a eficiência no tratamento da úlcera 
gástrica em ratos (Cheng et al. 2004) e na aceleração da cicatrização, particularmente em casos de póscirurgia crônica e ferimentos pós-trauma (WHO 1999).

A espécie Cymbopogon citratus (D.C.) Stapf., pertence à família Poaceae, é conhecida popularmente por mais de 20 nomes, dentre estes capim-limão e capim-santo. A origem desta espécie é o Sudoeste asiático, e distribui-se atualmente nas regiões tropicais e subtropicais (Gomes \& Negrelle 2003). É encontrada em todo o território brasileiro e comumente citada em levantamentos de plantas medicinais e estudos etnobotânicos (Albuquerque \& Andrade 2002; Amorozo 2002; Medeiros et al. 2004). Possui hábito herbáceo, crescendo em touceiras de mais de $1 \mathrm{~m}$, sendo as folhas ricas em óleos essenciais, contendo principalmente citral (Lewinsohn et al. 1998). Foi observado efeito antiinflamatório em ratos (Carbajal et al. 1989), atividade antibacteriana frente a cepas isoladas de infecção urinária (Pereira et al. 2004), atividade antimicrobiana (Díaz \& Jorge 2001) e efeito antigenotóxico (Cápiro et al. 2001).

Este trabalho teve por finalidade avaliar a qualidade dos produtos a base de castanha-da-índia, capim-limão e centela comercializados em farmácias do Recife, verificando sua adequação às exigências farmacopéicas e a legislação específica.

\section{Material e métodos}

Levantamento dos produtos à base de plantas medicinais comercializados na cidade do Recife Realizou-se um levantamento, com a participação dos autores deste trabalho, dos produtos à base de plantas medicinais em 54 estabelecimentos comerciais (Nascimento et al. 2005a), entre março e agosto de 2002, representados por duas redes de supermercados (totalizando 11 estabelecimentos) e duas redes de farmácias (num total de 43 estabelecimentos) que foram escolhidos por se distribuírem de forma homogênea nos seis distritos sanitários, tal como é dividida a cidade do Recife pela Secretaria Municipal de Saúde. Em cada estabelecimento foi aplicada uma ficha padronizada para catalogação dos produtos que continham plantas medicinais ou seus derivados. Para cada produto foram colhidas informações dos rótulos ou bulas, como o nome comercial do produto, a composição vegetal, a forma farmacêutica, as indicações terapêuticas e o laboratório envolvido na produção.

Os produtos catalogados foram classificados em três categorias, de acordo com sua forma física: produtos sólidos, semi-sólidos e líquidos. Foram enquadrados como produtos sólidos às formas farmacêuticas tais como comprimidos, cápsulas, drágeas, produtos pulverizados, pastilhas, sabonetes, sachês contendo partes de plantas medicinais trituradas, embalagens contendo partes inteiras das plantas. Fizeram parte da categoria de líquidos as soluções orais, xaropes, sprays bucais, elixires, óleos essenciais, tinturas, suspensões, sabonetes líquidos e outros correlatos. Os produtos semi-sólidos correspondiam às cápsulas gelatinosas, pomadas, cremes, géis e sabonetes cremosos.

Após o levantamento foram selecionados produtos, na forma sólida, à base de três plantas medicinais de grande ocorrência e comercialização para realizar o controle de qualidade, seguindo os procedimentos de Melo et al. (2004). Vinte e sete marcas comerciais diferentes foram adquiridas, sendo onze à base de capim-limão, dez de castanha-da-índia e seis de centela. A maioria desses produtos, obtidos para análise, abrange o mercado nacional sendo as indústrias envolvidas na produção pertencentes aos seguintes estados: São Paulo (10 produtos), Paraná e Pernambuco (com cinco produtos cada), Rio de Janeiro (três), e Amazonas, Minas Gerais, Rio Grande do Sul e Sergipe (um produto cada).

Análise de rótulos e bulas - As análises das informações técnico-científicas contidas nos rótulos e/ ou bulas dos produtos foram baseadas nas exigências e obrigatoriedades da legislação brasileira (Brasil 2000; Brasil 2003), específica para o assunto, e na literatura científica (WHO 1999; Teske \& Trentini 1997).

As informações botânicas analisadas foram a correta nomenclatura botânica oficial (gênero, espécie, autor do binômio e família), a composição vegetal do produto em relação ao informado no rótulo ou bula, a parte da planta utilizada e a informação da composição fitoquímica. Verificou-se as informações obrigatórias como ação, interações, riscos, modo de uso, reações adversas e as frases obrigatórias, recomendadas pela Resolução de Diretoria Colegiada (RDC) da Agência Nacional de Vigilância Sanitária (ANVISA) n. 140 de 29 de maio de 2003 (Brasil 2003).

Também foi utilizada a RDC n. 102 de 30 de novembro de 2000 que dispõe de regulamento sobre propagandas, mensagens publicitárias e promocionais e outras práticas cujo objeto seja a divulgação, promoção ou comercialização de medicamentos, de produção nacional ou importado, quaisquer que sejam as formas e meios de sua veiculação (Brasil 2000). Essa RDC foi usada devido à embalagem dos produtos 
serem utilizadas como meio de comunicação para promover as vendas dos mesmos.

Análise sensorial - Foram observadas, minuciosamente, as características sensoriais dos produtos em concordância com as monografias contidas na Farmacopéia Brasileira (2000; 2003). Este é um meio simples e rápido de verificar alguns parâmetros de qualidade, principalmente de identidade e pureza (Farias 2001).

Autenticidade da amostra - A autenticidade das amostras foi avaliada através de parâmetros contidos na Farmacopéia Brasileira (2000; 2003) e na literatura específica (Oliveira et al. 1991; Matos 1995; Ferro et al. 1996; Teske \& Trentini 1997), por meio de análises microscópicas (Melo et al. 2004), bem como por meio de reações de caracterização de constituintes químicos. A visualização dos caracteres microscópicos das espécies vegetais dos produtos em estado pulverizado foi feita diretamente ao microscópio óptico. As estruturas microscópicas foram comparadas com a descrição da droga na Farmacopéia Brasileira (2000; 2003) e literatura específica (Oliveira et al. 1991).

Os testes fitoquímicos realizados visaram evidenciar as principais classes de metabólitos presentes nas amostras, por reação de complexação química, com reagentes específicos para cada classe (Matos 1995). Os extratos alcoólicos foram preparados a partir de $5 \mathrm{~g}$ de cada amostra mantidos em repouso por 48 horas, sendo em seguida filtrados, procedendo-se os testes fitoquímicos. As classes de substâncias testadas foram: fenóis, taninos hidrolisáveis e condensados, flavonóides e saponinas. Também se realizou cromatografia em camada delgada (CCD) para confirmação, em sílica-gel $60 \mathrm{~F}_{254}$, com espessura de $0,2 \mathrm{~mm}$ como suporte. A fase móvel, para alcalóides, foi constituída de acetato de etila, ácido fórmico, ácido acético e água destilada (100:11:11:27 v/v), tendo como revelador o Dragendorff (Wagner \& Blandt 1996). Para saponinas o eluente usado foi clorofórmio, ácido acético glacial, metanol e água destilada (64:32:12:8 $\mathrm{v} / \mathrm{v}$ ), sendo revelado com vanilina sulfúrica (Wagner $\&$ Blandt 1996). Para triterpenos o eluente usado foi acetato de etila, ácido acético glacial, ácido fórmico e água (100:11:11:26 v/v), tendo como revelador o Lieberman/Burchard (Harbone 1984).

Verificação de pureza - A verificação da pureza baseou-se na determinação de elementos estranhos, cinzas totais e do teor de umidade. A determinação de cinzas totais foi realizada de acordo com o procedimento da Farmacopéia Brasileira (2000; 2003), e comparada com o percentual mínimo exigido na monografia da espécie. Considerou-se como elementos estranhos tudo aquilo que não era preconizado como parte constituinte da droga vegetal, de acordo com as monografias específicas (Melo et al. 2004). Para o teste de umidade foi usado o método gravimétrico, de acordo com os procedimentos contidos na Farmacopéia Brasileira (Melo et al. 2004).

\section{Resultados}

Análise de rótulos e bulas - Considerando o total de análises realizadas verificou-se que apenas dois produtos $(7,41 \%)$ possuíam as informações técnicocientíficas exigidas pela legislação de maneira irrepreensível (um a base de centela e outro a base de castanha-da-índia). Apenas cinco produtos apresentaram suas informações em bulas, e destes nenhum era constituído por capim-limão.

Verificou-se uma baixa menção das informações requeridas pela RDC 140 de 29 de maio de 2003 (Tab. 1). Informes sobre a composição qualitativa e quantitativa dos princípios ativos, ação do produto, riscos, frases obrigatórias, reações adversas e conduta em caso de superdosagem estiveram ausentes na maioria dos produtos $(92,59 \%)$, sobretudo naqueles a base de capim-limão (100\%).

Perante a RDC 102, a ausência de informes sobre a contra-indicação principal, a sugestão da inexistência de efeitos colaterais ou adversos e a baixa menção de advertência "Ao persistirem os sintomas, o médico deverá ser consultado" foram os problemas mais freqüentes nos produtos analisados (Tab. 2). Quanto às indicações terapêuticas atribuídas aos produtos verificou-se que nem todos possuem comprovação científica que suportem as propriedades biológicas sugeridas (Tab. 3).

Análise sensorial - As amostras de castanha-da-índia e capim-limão analisadas se apresentaram adequadas frente às características sensoriais, de acordo com as monografias na Farmacopéia Brasileira (2003). As primeiras possuíam odor fraco, com sabor levemente adstringente, produzindo salivação quando levado a boca, com cor variando entre marrom-claro e marromescuro. As segundas apresentaram odor característico de citral e sabor cítrico, com cor das amostras de marrom a verde-escuro. Embora a Farmacopéia Brasileira não descreva as características organolépticas para a centela, as amostras se apresentaram verde-escuro, sem odor ou sabor característicos. 
Tabela 1. Presença de informações obrigatórias para o consumidor exigida pela RDC 140 de 29 de maio de 2003, nos produtos analisados a base de centela, castanha-da-índia e capim-limão (Pesquisa realizada em 2005).

\begin{tabular}{|c|c|c|c|c|}
\hline Informações obrigatórias & $\begin{array}{l}\text { Total de produtos com } \\
\text { a presença de } \\
\text { informações obrigatórias } \\
(\%)\end{array}$ & $\begin{array}{l}\text { Número de produtos } \\
\text { e percentual para } \\
\text { amostras a base de } \\
\text { centela }\end{array}$ & $\begin{array}{l}\text { Número de produtos } \\
\text { e percentual para } \\
\text { amostras a base de } \\
\text { castanha-da-índia }\end{array}$ & $\begin{array}{l}\text { Número de produtos } \\
\text { e percentual para } \\
\text { amostras a base de } \\
\text { capim-limão }\end{array}$ \\
\hline $\begin{array}{l}\text { Completa Nomenclatura } \\
\text { Botânica Oficial }\end{array}$ & $7(25,93 \%)$ & $4(66,67 \%)$ & $3(30 \%)$ & 0 \\
\hline Via de administração & $19(70,37 \%)$ & $5(83,33 \%)$ & $7(70 \%)$ & $7(63,64 \%)$ \\
\hline Forma farmacêutica & $17(62,96 \%)$ & $6(100 \%)$ & $9(90 \%)$ & $2(18,18 \%)$ \\
\hline $\begin{array}{l}\text { Composição qualitativa e } \\
\text { quantitativa dos princípios ativos }\end{array}$ & $2(7,41 \%)$ & $1(16,67 \%)$ & $1(10 \%)$ & 0 \\
\hline A ação do produto & $3(11,11 \%)$ & $2(33,33 \%)$ & $1(10 \%)$ & 0 \\
\hline As indicações do produto & $15(55,55 \%)$ & $5(83,33 \%)$ & $8(80 \%)$ & $2(18,18 \%)$ \\
\hline Os riscos do produto & $4(14,81 \%)$ & $2(33,33 \%)$ & $2(20 \%)$ & 0 \\
\hline Presença de frases obrigatórias & $11(40,74 \%)$ & $5(83,33 \%)$ & $6(60 \%)$ & 0 \\
\hline Especificação do modo de uso & $23(85,19 \%)$ & $6(100 \%)$ & $8(80 \%)$ & $9(81,82 \%)$ \\
\hline Exibição de possíveis reações adversas & $1(3,70 \%)$ & $1(16,67 \%)$ & 0 & 0 \\
\hline $\begin{array}{l}\text { Especificação de conduta em caso } \\
\text { de superdose }\end{array}$ & $2(7,41 \%)$ & $2(33,33 \%)$ & 0 & 0 \\
\hline Citação dos cuidados de conservação & $17(62,96 \%)$ & $6(100 \%)$ & $7(70 \%)$ & $4(36,36 \%)$ \\
\hline Possui registro no Ministério da Saúde & $16(59,26 \%)$ & $6(100 \%)$ & $7(70 \%)$ & $3(27,27 \%)$ \\
\hline
\end{tabular}

Autenticidade das amostras - As estruturas observadas ao microscópio óptico, para os oito produtos pulverizados a base de castanha-da-índia, foram fragmentos de células da epiderme de cor castanhoamarelada com forma arredondada, partes de tecido parenquimático, grãos de amido de forma ovóide e células achatadas e elípticas com gotas de lipídeos que lembram parênquima de reserva.

Foram observadas, nas amostras de centela, células poligonais de paredes curvas, estômatos paracíticos e estruturas que lembravam parênquima paliçádico. Não foi encontrado oxalato de cálcio em nenhuma das amostras. No entanto, a existência em abundância de materiais não característico das folhas indica a mistura com outras partes da mesma planta.

As folhas de capim-limão apresentaram células retangulares com paredes retilíneas e outras com paredes sinuosas, células secretoras de coloração castanha quando tratadas com lugol. Porém a observação ficou prejudicada devido ao estado físico da droga.

Os testes fitoquímicos comprovaram a existência das principais classes de compostos característicos da espécie Aesculus hippocastanum Linné. As classes presentes foram fenóis, taninos condensados, flavonóides, saponinas e triterpenos, sendo as duas últimas as principais classes. Para Cymbopogon citratus (DC.) Stapf., as classes encontradas foram fenóis, taninos condensados, flavonóides e saponinas (nove amostras), triterpenos e alcalóides. Todas as amostras de Centella asiatica (L.) Urban apresentaram fenóis, taninos condensados, flavonóides, alcalóides, saponinas e triterpenos. Os triterpenos são os principais constituintes químicos da centela. A cromatografia em camada delgada confirmou a presença de triterpenos (todas as amostras), saponinas (25 amostras) e alcalóides nas amostras de capim-limão e centela. Em duas amostras de capim-limão não foi possível detectar saponinas. Com base nas características farmacobotânicas e organolépticas, e no perfil fitoquímico das espécies, todas as amostras foram consideradas autênticas, ou seja, correspondiam às espécies citadas nos rótulos e/ou bulas. As amostras à base de castanha-da-índia corresponderam a espécie Aesculus hippocastanum L., as de capim-santo a espécie Cymbopogon citratus (D.C.) Stapf., e as de centela a espécie Centella asiatica (L.) Urban.

Verificação de pureza - Duas amostras de castanhada-índia, sete de capim-limão e todas de centela foram reprovadas no teor de umidade, pois o percentual se encontrava acima do recomendado pelas monografias farmacopéicas (Tab. 4).

Todas as amostras a base de centela ultrapassaram o percentual máximo (11\%) no teor de cinzas totais. As amostras de capim-limão e castanha-daíndia, apresentaram percentuais em concordância com o recomendado (Tab. 4). 
Tabela 2. Presença de termos obrigatórios e anunciações vedadas para publicação em produtos à base de centela, castanha-da-índia e capim-limão, de acordo com a RDC 102 de 30 de Novembro de 2000 (Pesquisa realizada em 2005).

\begin{tabular}{|c|c|c|c|c|}
\hline $\begin{array}{l}\text { Total } \\
\text { inforn }\end{array}$ & $\begin{array}{l}\text { de produtos com } \\
\text { a presença de } \\
\text { nações obrigatórias } \\
\quad(\%)\end{array}$ & $\begin{array}{l}\text { Número de produtos } \\
\text { e percentual para } \\
\text { amostras a base de } \\
\text { centela }\end{array}$ & $\begin{array}{l}\text { Número de produtos } \\
\text { e percentual para } \\
\text { amostras a base de } \\
\text { castanha-da-índia }\end{array}$ & $\begin{array}{l}\text { Número de produtos } \\
\text { e percentual para } \\
\text { amostras a base de } \\
\text { capim-limão }\end{array}$ \\
\hline \multicolumn{5}{|l|}{ Termos obrigatórios } \\
\hline $\begin{array}{l}\text { Constou de forma clara, em português, } \\
\text { e precisa a contra-indicação principal }\end{array}$ & $3(11,11)$ & $2(33,33 \%)$ & $1(10 \%)$ & 0 \\
\hline $\begin{array}{l}\text { Possui a advertência: "Ao persistirem } \\
\text { os sintomas, o médico deverá ser } \\
\text { consultado" }\end{array}$ & $8(29,63)$ & $4(66,67 \%)$ & $4(40 \%)$ & 0 \\
\hline \multicolumn{5}{|l|}{ Termos vedados } \\
\hline $\begin{array}{l}\text { Realizou comparações, de forma direta } \\
\text { ou indireta, que não estejam baseadas } \\
\text { em informações comprovadas por } \\
\text { estudos clínicos veiculados em } \\
\text { publicações indexadas. }\end{array}$ & $1(3,70)$ & 0 & 0 & $1(9,09 \%)$ \\
\hline $\begin{array}{l}\text { Incluiu mensagens verbais e não verbais, } \\
\text { que mascarem as indicações reais dos } \\
\text { produtos fitoterápicos }\end{array}$ & $1(3,70)$ & 0 & 0 & $1(9,09 \%)$ \\
\hline $\begin{array}{l}\text { Sugeriu ausência de efeitos colaterais ou } \\
\text { adversos ou utiliza expressões tal como: } \\
\text { "inócuo", "seguro", ou "produto natural" }\end{array}$ & $7(25,93)$ & 0 & $1(10 \%)$ & $6(54,55 \%)$ \\
\hline $\begin{array}{l}\text { Estimulou e/ou induziu o uso indiscrimi- } \\
\text { nado de medicamentos fitoterápicos e/ } \\
\text { ou emprego de dosagens e indicações } \\
\text { que não constem no registro do produto } \\
\text { junto a ANVISA }\end{array}$ & $4(14,81)$ & 0 & 0 & $4(36,36 \%)$ \\
\hline $\begin{array}{l}\text { Afirmou que o produto fitoterápico é } \\
\text { "seguro", "sem contra-indicações", } \\
\text { "isento de efeitos secundários ou riscos } \\
\text { de uso" ou usa expressões equivalentes }\end{array}$ & $1(3,70)$ & $1(16,67 \%)$ & 0 & 0 \\
\hline $\begin{array}{l}\text { Usou de linguagem direta ou indireta } \\
\text { relacionando o uso do produto ao } \\
\text { desempenho físico, intelectual, } \\
\text { emocional, sexual ou beleza de uma pessoa }\end{array}$ & $1(3,70)$ & 0 & 0 & $1(9,09 \%)$ \\
\hline
\end{tabular}

Cinco amostras de capim-limão possuíam elementos estranhos acima do permitido, não sendo possível proceder com esta análise com as demais devido à fragmentação do material (Tab. 4).

Os percentuais acima do recomendado nas análises de pureza e a ausência das informações técnicas e essenciais ao consumidor, foram as principais causas da reprovação dos produtos analisados.

\section{Discussão}

O resultado obtido na análise de rótulos e bulas confirma o desleixo com as informações necessárias para o uso racional e correto dos produtos. A ausência de bulas em 22 produtos é um problema sério, uma vez que a bula é o principal instrumento de informações para o consumidor (Silva et al. 2000). Resultado semelhante foi obtido em Porto Alegre por Bello et al. (2002), onde dos 65 fitoterápicos analisados 51\% não possuíam bula. A ausência ou apresentação de informações obrigatórias de maneira incompleta demonstra a necessidade de padronização e inserção de informações essenciais ao paciente em produtos à base de plantas medicinais, com fins terapêuticos, comercializados em estabelecimentos oficiais, a fim de possibilitar o uso consciente e correto pelo consumidor. 
Tabela 3. Síntese das indicações, transcritas literalmente dos rótulos e bulas, dos produtos à base de centela, capim-limão e castanha-daíndia comercializados em farmácias e supermercados da cidade do Recife, PE (Pesquisa realizada em 2005).

Planta Indicações atribuídas pelos produtos

centela - "câimbras, formigamento, varizes, celulite, emagrecimento, combate à gordura localizada, tratamento da insuficiência venosa, úlceras estomacais e duodenais, cicatrização de feridas, afecções cutâneas, eczemas, hematomas, cicatrização pós cirurgia, auxiliar no tratamento das varizes, varicose, coadjuvante no tratamento da celulite, insuficiência venosa crônica, hipertensão venosa e no tratamento da insuficiência venosa"

capim-limão - “insônia, nervosismo, dor de cabeça, cólicas no ventre, gases, reumatismo, febres, gripes, problemas

castanha-da-índia-"hemorróidas, analgésico, varizes, flebites, úlceras varicosas, prevenção de varizes e hemorróidas, síndrome de pernas cansadas, machucaduras musculares, hematomas, problemas vasculares periféricos em geral, auxiliar nos casos de varizes e hemorróidas, tônico, circulatório, vaso constritor, diversos quadros febris, gota, dores de origem reumática, traumatismo, auxiliar nas perturbações da circulação venosa, preventiva de varizes e hemorróidas, fortalece as paredes dos vasos diminuindo a fragilidade capilar, problemas circulatórios" digestivos, dores e musculares"

Indicações suportadas por dados experimentais

Tratamentos de feridas, queimaduras e doenças ulcerosas da pele, prevenção de manchas do tecido e escoriações hipertróficas. Os extratos da planta têm sido usados atualmente para acelerar a cicatrização, particularmente em casos de pós-cirurgia crônica e ferimentos pós-trauma. Extratos têm sido administrados oralmente para tratar estresse estomacal induzido e úlceras duodenais (WHO 1999)

Antiinflamatório (Carbajal et al. 1989), antimicrobiano (Diaz \& Jorge 2001)

Internamente, para o tratamento sintomático da insuficiência venosa crônica, incluindo dores, sensibilidade fortemente nas pernas, espasmos musculares noturnos, coceiras e edema. Externamente, para o tratamento sintomático da insuficiência venosa crônica, distensões e contusões (WHO 1999)

implicando num problema sanitário.

A espécie Centella asiatica (L.) Urban tem para esse quadro atual, a comercialização de produtos à base de plantas medicinais com finalidade alimentícia, sendo assim dispensados de apresentarem informações técnico-científicas em bulas. Contudo, não parece adequado à venda de produtos a base de espécies vegetais medicinais (como as apresentadas neste trabalho) com finalidade nutricional, pois: I - Há a comprovação científica das propriedades farmacológicas de grande parte dessas plantas; II Existem restrições para o uso como contra-indicações, interações medicamentosas ou alimentares, reações adversas e precauções; III - Muitas são comercializadas apresentando indicações terapêuticas; IV- Muitas espécies medicinais têm apresentado efeitos tóxicos.

Atualmente, a literatura científica tem disponibilizado, com acesso facilitado, informações sobre plantas medicinais nas áreas de botânica, química, farmacologia, farmacotécnica e outras disciplinas correlatas, que vêm sendo divulgadas em artigos científicos, livros técnicos e monografias especializadas como as farmacopéias. Mesmo assim a indústria não tem feito menção a essas informações obrigatórias, seja por negligência ou falta de exigências legais, apresentado, em alguns casos, efeito hepatotóxico (Jorge \& Jorge 2005), efeitos depressores do Sistema Nervoso Central quando consumida em altas doses (acima de $50 \mathrm{mg}$ por Kg de peso) (Teske \& Trentini 1997), possível implicação de carcinogênese de pele (demonstrado em roedores após repetidas aplicações tópicas), dermatite alérgica associada com a aplicação tópica (WHO 1999), prurigem e fotossensibilidade (Capasso et al. 2000), sendo contra-indicado seu uso a quem tenha alergia a alguma planta da família Apiaceae (WHO 1999). Para Aesculus hippocastanum L. relata-se dano hepático (Capasso et al.2000), hipersensibilidade, potencialização da ação de anticoagulantes, toxicidade em doses elevadas (Teske \& Trentini 1997). É contra-indicada para pessoas com alergia a alguma planta da família Hippocastanaceae, e se consumida em altas doses poderá causar nefropatia tóxica. Pode apresentar reações adversas como náuseas, desconforto estomacal e reações alérgicas (WHO 1999). Cymbopogon citratus (DC) Stapf pode causar, em caso de superdosagem, hipocinesia, ataxia, bradipnéia, perda de postura, sedação e diarréia (Teske \& Trentini 
Tabela 4. Teor de umidade, cinzas totais e elementos estranhos para os produtos à base de castanha-da-índia (CA), capim-limão (CP) e centela (CE) comercializados na cidade do Recife, PE (Pesquisa realizada em 2005). * = Produtos encapsulados e/ou pulverizados; $* *=$ Produtos sem elementos estranhos visíveis. Limites desejáveis: $\mathrm{CA}=$ Teor de umidade $(10 \%)$, Teor de cinzas totais $(4 \%)$; $\mathrm{CP}=\mathrm{Teor}$ de umidade (11\%), Teor de cinzas totais $(9 \%)$, matéria estranha $(1 \%)$; $\mathrm{CE}=$ Teor de umidade $(6 \%)$, Teor de cinzas $(11 \%)$.

\begin{tabular}{|c|c|c|c|c|}
\hline Amostras & $\begin{array}{c}\text { Teor de umidade } \\
(\%)\end{array}$ & $\begin{array}{c}\text { Teor de cinzas totais } \\
(\%)\end{array}$ & $\begin{array}{c}\text { Elementos estranhos } \\
(\%)\end{array}$ & Situação \\
\hline CA1 & 7,06 & 2,58 & $*$ & Aprovado \\
\hline $\mathrm{CA} 2$ & 6,86 & 2,40 & $*$ & Aprovado \\
\hline CA3 & 5,49 & 2,04 & $*$ & Aprovado \\
\hline CA4 & 6,03 & 1,17 & $*$ & Aprovado \\
\hline CA5 & 7,05 & 2,25 & $*$ & Aprovado \\
\hline CA6 & 7,74 & 1,88 & $*$ & Aprovado \\
\hline $\mathrm{CA} 7$ & 7,47 & 2,50 & $*$ & Aprovado \\
\hline CA8 & 6,53 & 1,82 & $*$ & Aprovado \\
\hline CA9 & 11,67 & 2,70 & $*$ & Reprovado \\
\hline CA10 & 13,32 & 1,02 & $* *$ & Reprovado \\
\hline CP1 & 11,60 & 6,39 & 47,20 & Reprovado \\
\hline $\mathrm{CP} 2$ & 10,34 & 6,67 & 0,81 & Aprovado \\
\hline $\mathrm{CP} 3$ & 12,15 & 6,07 & 14,40 & Reprovado \\
\hline $\mathrm{CP} 4$ & 12,50 & 6,98 & 45,50 & Reprovado \\
\hline CP5 & 12,03 & 6,61 & 3,33 & Reprovado \\
\hline CP6 & 13,05 & 6,28 & 5,74 & Reprovado \\
\hline CP7 & 10,72 & 7,08 & $*$ & Aprovado \\
\hline CP8 & 11,66 & 5,78 & $*$ & Reprovado \\
\hline CP9 & 11,58 & 5,16 & $* *$ & Reprovado \\
\hline CP10 & 11,01 & 5,40 & $* *$ & Reprovado \\
\hline CP11 & 10,91 & 6,87 & $*$ & Aprovado \\
\hline CE1 & 11,81 & 14,40 & $*$ & Reprovado \\
\hline CE2 & 12,27 & 12,42 & $*$ & Reprovado \\
\hline CE3 & 10,93 & 12,12 & $*$ & Reprovado \\
\hline CE4 & 12,57 & 11,86 & $*$ & Reprovado \\
\hline CE5 & 12,32 & 18,14 & $*$ & Reprovado \\
\hline CE6 & 10,26 & 22,02 & $*$ & Reprovado \\
\hline
\end{tabular}

1997). Elevadas doses do extrato alcoólico dessa planta administrado em ratos causou efeito hepatotóxico e nefrotóxico (Guerra et al. 2000). Sendo assim, a presença de informações obrigatórias para o paciente, como as descritas na tabela 1, são imprescindíveis em produtos a base de plantas medicinais comercializados em estabelecimentos oficiais como farmácias e drogarias. Quanto às anunciações vedadas para publicação, constata-se que muitos produtos utilizam mensagens publicitárias indutoras de consumo que transmitem a idéia de que não podem ocasionar reações tóxicas e efeitos adversos e/ou não possuam contra-indicações por serem "naturais", transgredindo assim a RDC 102.

Quanto às indicações terapêuticas observou-se que não há uma padronização técnica dos termos, pois de acordo com a legislação é obrigatório (Brasil 2003) ao se referir a sinais, sintomas e doenças, utilizar a terminologia preconizada pela Classificação Internacional de Doenças, o CID 10. Também há uma grande quantidade de indicações terapêuticas sem comprovação científica, como por exemplo o tratamento de celulite pela Centella asiatica (L.) Urban, que segundo a Organização Mundial da Saúde, é um uso descrito na medicina popular, não suportado por experimentação ou dados clínicos (WHO 1999). Além disso, no Brasil, os extratos de Aesculus hippocastanum L. só devem ser comercializados com indicações para fragilidade capilar e insuficiência venosa, e os extratos à base de Centella asiatica (L.) Urban para o tratamento de insuficiência venosa dos membros inferiores (Brasil 2004).

A ausência dos nomes científicos e da parte da planta utilizada nos produtos abre uma brecha para a adulteração e favorece a introdução de outras partes vegetais que não contenham o princípio ativo desejado ou o possuam em baixa quantidade. O princípio ativo de Aesculus hippocastanum L., a escina, pôde ser detectado de forma indireta por meio da verificação 
da presença de saponinas triterpênicas. A presença deste componente químico confere à droga propriedades farmacológicas como antiinflamatória, no tratamento de hemorróidas, e contra insuficiência venosa crônica, além de uma significante atividade para o edema pós-operatório (Sirtori 2001). A presença de triterpenos nas amostras de centela sugere que os seus principais constituintes ativos (ácido asiático, ácido medecássico, e asiaticosídeo) estão presentes, os quais estão implicados no tratamento da insuficiência venosa crônica e veias varicosas (Inamdar et al. 1996). O resultado negativo para saponinas em duas amostras de capim-limão indica ausência ou baixíssima concentração do mesmo.

O alto teor de água nas amostras analisadas diminui o valor farmacológico da droga e pode até anulá-lo, pois o excesso de água permite a ação de enzimas, podendo acarretar a degradação de substâncias ativas, além de facilitar o aparecimento e desenvolvimento de microorganismos (Farias 2001). A alta percentagem de cinzas nas amostras de centela aponta para a presença de contaminantes inorgânicos não-voláteis.

As cinco amostras de capim-limão com excesso de elementos estranhos é um problema freqüente dos produtos à base de plantas medicinais comercializados no Brasil (Barbosa et al. 2001; Duarte \& Bardal 2002; Brandão et al. 2002). No Recife, Melo et al. (2004) constataram que 100\% das amostras de boldo (Peumus boldus Molina) e 55,56\% das amostras de pata-devaca (Bauhinia spp.) possuíam excesso de constituintes indesejáveis. A grande quantidade de impurezas devese a um processo inadequado de separação das partes vegetais condizentes com as monografias específicas e de uma limpeza precária na produção dos mesmos.

Concluindo: os produtos à base de castanha-daíndia, centela e capim-limão carecem de informações técnico-científicas que propiciem o seu uso correto e racional; todos os produtos a base de centela e alguns a base de castanha-da-índia e capim-santo podem oferecer riscos ao consumidor e/ou ausência de eficácia devido ao elevado teor de impurezas; faz-se necessário uma maior intensificação na vigilância de produtos a base de plantas medicinais comercializados no Brasil.

\section{Agradecimentos}

Ao Ministério da Saúde/Fundação de Amparo a Ciência e Tecnologia do Estado de Pernambuco (FACEPE), pelo apoio financeiro; ao CNPq/UFRPE, pela concessão de bolsas iniciação científica; ao CNPq, pela bolsa de mestrado concedida ao primeiro autor.

\section{Referências bibliográficas}

Albuquerque, U.P. \& Andrade, L.H.C. 2002. Uso de recursos vegetais da caatinga: o caso do agreste do estado de Pernambuco (Nordeste do Brasil). Interciencia 27(7): 336-346.

Albuquerque, U.P.; Monteiro, J.M.; Ramos, M.A. \& Amorim, E.L.C. 2007. Medicinal and magic plants from a public market in northeastern Brazil. Journal Ethnopharmacology 110: 76-91.

Amaral, F.M.M.; Coutinho, D.F.; Ribeiro, M.N.S. \& Oliveira, M.A. 2003. Avaliação da qualidade de drogas vegetais comercializadas em São Luís, Maranhão. Revista Brasileira de Farmacognosia 13(1): 27-30.

Amorozo, M.C.M. 2002. Uso e diversidade de plantas medicinais em Santo Antônio do Leverger, MT, Brasil. Acta Botanica Brasilica 16(2): 189-203.

Barbosa, M.C.S.; Belletti, K.M.S.; Corrêa, T.F. \& Santos, C.A.M. 2001. Avaliação da qualidade de folhas de boldodo-chile (Peumus boldus Molina) comercializadas em Curitiba, PR. Revista Brasileira de Farmacognosia 11(1): $1-4$.

Bello, C.M.; Montanha, J.A. \& Schenkel, E.P. 2002. Análise das bulas de medicamentos fitoterápicos comercializados em Porto Alegre, RS, Brasil. Revista Brasileira de Farmacognosia 12(2): 75-83.

Brandão, M.G.L.; Alves, R.M.S.; Moreira, R.A.; Oliveira, P.; Vieira, M.T. \& Moreira-Campos, L.M. 2002. Qualidade de amostras comerciais de chás de plantas medicinais. Revista Brasileira de Plantas Medicinais 5(1): 56-59.

Brasil. 2000. Resolução da diretoria colegiada da Anvisa (RDC) n. 102, de 30 de novembro de 2000. http:// www.anvisa.gov.br/e-legis/

Brasil. 2003. Resolução da Diretoria Colegiada (RDC) n. 140, de 29 de maio de 2003. http://www.anvisa.gov.br/e-legis/

Brasil. 2004. Resolução da Anvisa (RE) n. 89, de 16 de março de 2004. http://www.anvisa.gov.br/e-legis/

Cañigueral, S.; Dellacassa, E. \& Bandoni, A.L. 2003. Plantas Medicinales y Fitoterapia: ¿ indicadores de dependencia o factores de desarrollo? Acta Farmacéutica Bonaerense 22(3): 265-278.

Capasso, R.; Izzo, A.A.; Pinto, L.; Bifulco, T.; Vitobello, C. \& Mascolo, N. 2000. Phytotherapy and quality of herbal medicines. Fitoterapia 71: S58-S65.

Cápiro, N.; Sanchez-Lamar, A.; Fonseca, G.; Baluja, L. \& Borges, E. 2001. Capacidad protectora de Cymbopogon citratus (DC.) Stapf. Ante el daño genético inducido por estrés oxidativo. Revista Cubana de Investigación Biomedica 20(1): 33-38.

Carbajal, D.; Casaco, A.; Arruzazabala, L.; Gonzalez, R. \& Tolon, Z. 1989. Pharmacological study of Cymbopogon citratus leaves. Journal of Ethnopharmacology 25: 103-107.

Carvalho, A.C.B.; Fernandez, M.G.; Santos, E.J.V.; Melo, A.F.M.; Medeiros, I.A. \& Diniz, M.F.F.M. 2004. Avaliação legal da propaganda e publicidade de medicamentos fitoterápicos anunciados na Paraíba (Brasil). Acta Farmacéutica Bonaerense 23(3): 413-417. 
Cheng, C.L. \& Koo, M.W.L. 2000. Effects of Centella asiatica on ethanol induced gastric mucosal lesions in rats. Life Sciences 67: 2647-2653.

Díaz, L.H. \& Jorge, M.R. 2001. Actividad antimicrobiana de plantas que crecen en Cuba. Revista Cubana de Plantas Medicinales 2: 44-47.

Duarte, M.R. \& Bardal, D. 2002. Qualidade de fármacos vegetais comercializados em Curitiba - PR. Revista Visão Acadêmica 3(2): 65-68.

Eldin, S. \& Dunford, A. 2001. Fitoterapia na atenção primária à saúde. São Paulo, Manole.

Engelke, F. 2003. Fitoterápicos e Legislação. Jornal Brasileiro de Fitomedicina 1(1): 10-15.

Farias, M.R. 2001. Avaliação da qualidade de matérias-primas vegetais. Pp. 197-220. In: C.M.O. Simões (ed.). Farmacognosia: da planta ao medicamento. Florianópolis, Universidade Federal de Santa Catarina.

Farmacopéia Brasileira. 2000. 4ª ed., segundo fascículo. São Paulo, Atheneu.

Farmacopéia Brasileira. 2003. $4^{\mathrm{a}}$ ed., quinto fascículo. São Paulo, Atheneu.

Farnsworth, N.R. 1997. Testando plantas para novos remédios. In: E.O. Wilson (ed.). Biodiversidade. Rio de Janeiro, Nova Fronteira.

Ferro, V.O.; Oliveira, I. \& Jorge, L.I.F. 1996. Diagnose comparativa de três espécies vegetais comercializadas como "ervas cidreiras" Lippia alba (Mill) N.E. Br. ex Britt \& Wilson, Cymbopogon citratus (D.C.) Stapf e Melissa officinalis L. Revista Lecta 14(2): 53-63.

Gomes, E.C. \& Negrelle, R.R.B. 2003. Cymbopogon citratus (D.C.) Stapf: Aspectos botânicos e ecológicos. Visão Acadêmica 4(2): 137-144.

Guerra, M.J.M.; Badell, J.B.; Albajes, A.R.R.; Pérez, H.B.; Valencia, R.M. \& Azcuy, A.L. 2000. Evaluación toxicológica aguda de los extractos fluidos al 30 y $80 \%$ de Cymbopogon citratus (D.C.) Stapf (caña santa). Revista Cubana de Plantas Medicinales 5(3): 97-101.

Harbone, J.B. 1982. Phytochemical methods. London, Chapman \& Hall.

Inamdar, P.K.; Yeole, R.D.; Ghogare, A.B. \& Souza, N.J. 1996. Determination of biologically active constituents in Centella asiatica. Journal of Chromatography 742: 127-130.

Jayashree, G.; Muraleedhara, G.K.; Sudarslal, S. \& Jacob, V.B. 2003. Anti-oxidant activity of Centella asiatica on lymphoma-bearing mice. Fitoterapia 74: 431-434.

Jorge, O.A. \& Jorge, A.D. 2005. Hepatotoxicity associated with the ingestion of Centella asiatica. Revista Espanhola de Enfermidades Digestivas 97(2): 115-124.

Lewinsohn, E.; Dudai, N.; Tadmor, Y.; Katzir, I.; Ravid, U.; Putievsky, E. \& Joel, D.M. 1998. Histochemical localization of citral accumulation in lemongrass leaves (Cymbopogon citratus (DC.) Stapf., Poaceae). Annals of Botany 81: 35-39.

Matos, F.J.A. 1995. Introdução a fitoquímica experimental. Fortaleza, Universidade Federal do Ceará.
Medeiros, M.F.T.; Fonseca, V.S. \& Andreata, R.H.P. 2004. Plantas medicinais e seus usos pelos sitiantes da reserva Rio das Pedras, Mangaratiba, RJ, Brasil. Acta Botanica Brasilica 18(2): 391-399.

Melo, J.G.; Nascimento, V.T.; Amorim, E.L.C.; Lima, C.S.A. \& Albuquerque, U.P. 2004. Avaliação da qualidade de amostras comerciais de boldo (Peumus boldus Molina), pata-de-vaca (Bauhinia spp.) e ginco (Ginkgo biloba L.). Revista Brasileira de Farmacognosia 14(2): 111-120.

Nascimento, J.E.; Lacerda, E.U.; Nascimento, V.T.; Melo, J.G.; Alves, B.S.; Silva, L.G.M.; Ramos, M.A.; Lima, C.S.A.; Albuquerque, U.P. \& Amorim, E.L.C. 2005a. Produtos a base de plantas medicinais comercializados em Pernambuco - Nordeste do Brasil. Acta Farmacéutica Bonaerense 24(1): 113-122.

Nascimento, V.T.; Lacerda, E.U.; Melo, J.G.; Lima, C.S.A.; Amorim, E.L.C. \& Albuquerque, U.P. 2005b. Controle de qualidade de produtos à base de plantas medicinais comercializados na cidade do Recife-PE: erva-doce (Pimpinella anisum L.), quebra-pedra (Phyllanthus spp.), espinheira santa (Maytenus ilicifolia Mart.) e camomila (Matricaria recutita L.). Revista Brasileira de Plantas Medicinais 7(3): 56-64.

Oliveira, F.; Akisue, G. \& Akisue, M.K. 1991. Farmacognosia. São Paulo, Atheneu.

Pereira, R.S.; Sumita, T.C.; Furlan, M.R.; Jorge, A.O.C. \& Ueno, M. 2004. Atividade antibacteriana de óleos essenciais em cepas isoladas de infecção urinária. Revista de Saúde Pública 38(2): 326-328.

Ramos, M.A.; Albuquerque, U.P. \& Amorim, E.L.C. 2005. O comércio de plantas medicinais em mercados públicos e feiras livres: um estudo de caso. Pp. 127-163. In: U.P. Albuquerque; C.F.C.B.R. Almeida \& J.F.A. Marins, (orgs.). Tópicos em Conservação, Etnobotânica e Etnofarmacologia de Plantas Medicinais e Mágicas. Recife, NUPEEA.

Silva, T.; Dal-Pizzol, F.; Bello, C.M.; Mengue, S.S. \& Schenkel, E.P. 2000. Bulas de medicamentos e a informação adequada ao paciente. Revista de Saúde Pública 34(2): 184-189.

Sirtori, C.R. 2001. Aescin: Pharmacology, pharmacokinetics and therapeutic profile. Pharmacological Research 44(3): 183-193.

Teske, M. \& Trentini, A.M.M. 1997. Herbarium: Compêndio de fitoterapia. Curitiba, Herbarium.

Vieira, R.A. 2001. Validação científica de plantas medicinais como fator catalisador no desenvolvimento da indústria farmacêutica nacional. Revista Saúde e Ambiente 2(1/2): 57- 64.

Zuccolotto, T.; Apel, M. \& Rates, S.M.K. 1999. Avaliação da qualidade de produtos fitoterápicos comercializados em Porto Alegre - RS. Revista do Instituto Adolfo Lutz 58(2): 25-31.

Wagner, H. \& Blandt, S. 1996. Plant Drug Analysis. New York, Springer.

World Health Organization 1999. Monographs on selected medicinal plants. Geneva, WHO Library Cataloguing in Publication Data. 